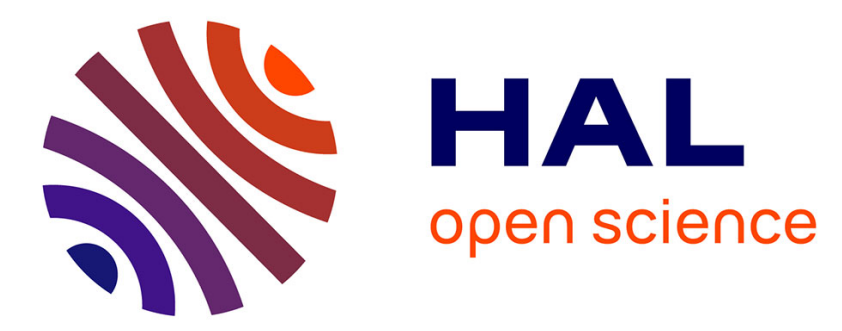

\title{
Coalition formation: the role of procedure and policy flexibility
}

Eligius Hendrix, Annelies de Ridder, Agnieszka Rusinowska, Elena Saiz

\section{To cite this version:}

Eligius Hendrix, Annelies de Ridder, Agnieszka Rusinowska, Elena Saiz. Coalition formation: the role of procedure and policy flexibility. Group Decision and Negotiation, 2013, 22 (3), pp.407-427. 10.1007/s10726-011-9276-0 . hal-00666849

\section{HAL Id: hal-00666849 https://hal.science/hal-00666849}

Submitted on 6 Feb 2012

HAL is a multi-disciplinary open access archive for the deposit and dissemination of scientific research documents, whether they are published or not. The documents may come from teaching and research institutions in France or abroad, or from public or private research centers.
L'archive ouverte pluridisciplinaire HAL, est destinée au dépôt et à la diffusion de documents scientifiques de niveau recherche, publiés ou non, émanant des établissements d'enseignement et de recherche français ou étrangers, des laboratoires publics ou privés. 


\title{
Coalition formation: the role of procedure and policy flexibility*
}

\author{
Eligius M.T. Hendrix $†$ Annelies de Ridder $\ddagger$ Agnieszka Rusinowska
}

\begin{abstract}
A spatial model of coalition formation is used together with data from Dutch elections and theoretical instances to study different procedures of coalition formation. The model shows that procedure plays an important role in reaching a coalition agreement and that political parties do not necessarily benefit from being a first-mover. Moreover, it is shown that a decrease in a party's flexibility can be (dis)advantageous in coalition negotiations. Furthermore, certain power sharing tactics appear not always to lead to an agreement that is in a party's advantage. The main message put forward is that the procedure of forming a coalition plays a more important role than is usually acknowledged in literature and practice.
\end{abstract}

Keywords: coalition formation, elections, maneuvering space, step-by-step procedure, simultaneous procedure, minimal winning coalition

JEL Classification: D72, C7

Running head: Coalition formation: procedures, flexibility

\section{Introduction}

In multi-party democracies, political parties have to form coalitions to achieve majority governments. As a part of coalition negotiations, coalition members bargain and agree on a package, the so-called coalition agreement. Timmermans, 2003, provides an extensive discussion on coalition agreements. Such coalition agreements were reached in $63 \%$ of coalition formations in Western-Europe studied by Müller and Strøm (2003), e.g. Austria, Ireland, Belgium and The Netherlands. In order to reach such a coalition agreement, parties in the coalition have to make compromises deviating from its own ideal policy. The flexibility of political parties in the negotiations on coalition agreements is one of the central subjects of this paper.

This article aims at a contribution in the field of political science, in particular, in formal and spatial coalition modeling. The field of research of formal coalition models is large and

\footnotetext{
*We like to thank the anonymous referees and editor for their useful comments that helped to improve the paper. The Spanish Ministry of Science and Innovation is acknowledged for project TIN2008-01117. One of the authors is a fellow of the Spanish "Ramon y Cajal" contract program, co-financed by the European Social Fund.

${ }^{\dagger}$ Universidad de Málaga and Wageningen University, E-mail: Eligius.Hendrix@wur.nl

${ }^{\ddagger}$ Radboud University Nijmegen, The Netherlands, E-mail: anneliesderidder@gmail.com

${ }^{\S}$ Corresponding author, CNRS - Université Paris I Panthéon-Sorbonne, Centre d'Economie de la Sorbonne, 106-112 Bd de l'Hôpital, 75647 Paris, France, E-mail: agnieszka.rusinowska@univ-paris1.fr

`Radboud University Nijmegen, The Netherlands, E-mail: elenasap@terra.es
} 
extensive, see, amongst others, Von Neumann and Morgenstern (1944), Downs (1957), Axelrod (1970), Grofman (1982), Van Deemen (1989), Laver and Shepsle (1996), Warwick (1998), De Vries (1999) and Martin and Stevenson (2001). So far, most of those studies have focused on why coalition form and, based on that, which parties will cooperate. Arguments for coalition formation were found in power, policy, or institutional arguments. However, the strategy and process of coalition formation have been ignored in the literature (Laver \& Schofield, 1990): how will coalitions be formed, and, what is the best strategy for a party during the process of coalition formation? Also, from a more formal theoretical point of view, several authors have pointed at this lack of dynamics in the models (Van Deemen, 1997; Tohmé \& Sandholm, 1999; Arnold \& Schwalbe, 2002).

Coalition formation is clearly dynamic in nature: for example, parties need a few weeks, sometimes months, to reach a coalition agreement, different procedures are used to form a coalition, and parties move their positions to be able to compromise. Roughly speaking, two different ways of coalition formation can be discerned: a step-by-step or hierarchical procedure versus a simultaneous or non-hierarchical procedure (Laver \& Schofield, 1990). The step-bystep approach sees coalition formation as a process in which the group incrementally forms: new members are added gradually. An alternative approach is to negotiate immediately with all the members of the coalition, as in a simultaneous procedure. So far literature has paid little attention to the consequences of these procedures for the result of coalition formation. Some earlier research (Austen-Smith \& Banks, 1988; Baron, 1993; Bloch, 1996; Brams et al., 2005; De Ridder \& Rusinowska, 2008) showed why this may be of importance. However, this earlier research has not evolved towards a coherent and empirically verified stream of research, and, moreover, the role of procedure has been ignored.

In this paper, we study the two dynamical aspects of coalition formation (procedure and policy flexibility) by analyzing a formal model and deducing implications from this model based on real-life data. The model has been described in De Ridder and Rusinowska (2008), where it was applied to alliance formation between firms under different procedures. In Sáiz et al. (2007), the computational aspects of both the model and the empirical test are discussed. Our research questions focus on two major points and one minor point concerning the strategies political parties should adopt during the process of coalition negotiations.

The first major point is to stress the role of coalition formation procedure. Two different procedures of coalition formation, leading to different coalition positions, are under study. We validate earlier theoretical results due to De Ridder and Rusinowska (2008). They show among others that there is no procedure which is always better. Furthermore, we focus on the firstmover advantage. The question is whether being a first-mover is always advantageous for a party in coalition negotiations, as in real-life the biggest party, after elections, is most often rewarded with the initiative for coalition negotiations.

As a second major point, we focus on policy flexibility of parties. One of the characteristics of the spatial model is that parties have maneuvering spaces which reflect their flexibility to deviate from their ideal positions. The idea that no party will accept a coalition position outside its maneuvering space is similar to the one of a policy-horizon model by Warwick (2000, 
2005a, 2005b). Warwick examines the hypothesis that coalition government formation in West European parliaments is constrained by the existence of limits or bounds (called policy horizons) on the extent to which parties can compromise on their policy positions in order to participate in government. The maneuvering space of parties in the model is therefore equivalent to the policy horizon considered by Warwick. While Warwick focuses on developing methods to estimate these policy horizons and on applying the methods to data on West European parliamentary systems, our aim is different. In this article we neither aim at estimating the maneuvering spaces nor at forecasting which coalition will form, rather we focus on the procedure to reach a coalition and on the strategies the parties may adopt in this procedure. Moreover, we consider different dynamic procedures of forming two- or multi-party coalitions (governments), which uniquely determine the policy positions of the coalitions (governments). Then, for each party, we determine preference orderings of different coalitions. Apart from the question on implications for procedure, the question we pose is if being flexible in coalition negotiations is advantageous for parties. Is a party better off by being more or less flexible?

A minor point under study is the role of sharing power. The question here is whether striving for a coalition in which a party gets the best relative power position is always advantageous. Earlier empirical results confirm the role of power-sharing motives of parties (Martin \& Stevenson, 2001), but do not show that oversize can be an advantage for coalition members. Volden and Carrubba (2004) explain when oversized coalitions occur. Sub-issues here are the minimal winning argument (Von Neumann \& Morgenstern, 1944) and the influence of weight. The minimal winning argument states that only coalitions will form that have enough members to be winning, but not more than that. Is a smaller coalition necessarily more advantageous for a participating party? Concerning weight, we like to consider the consequence the weight of a party (number of seats in parliament) has for its coalitional partners. Does an increase of a party's weight imply a disadvantage for its coalition partners?

Those questions are investigated deducing implications on coalition formation dynamics using the theoretical model. Calculations are done with the model using data from Dutch politics and several theoretical instances. Both the empirical and theoretical calculations provide counter-intuitive situations which show that certain expectations do not always hold and that certain traditions in real-life coalition formation are not necessarily advantageous. Advantageous is defined in terms of preference of a party over a coalition and the path to reach this coalition. This is measured by taking the distance from the ideal position of the party to the position of the coalition compromise, and the smaller the distance, the better. The policy-distance effect on government composition, i.e. the incentive of a party to join a parliamentary coalition government decreases with the distance between the policy position and the position of the government, was elaborated and tested in particular by Warwick (1998).

This paper is organized as follows. Section 2 presents the theoretical background and rephrases the research questions in terms of hypotheses. In Section 3, we elaborate on Dutch data and the way we calculate in the model. Section 4 shows counter examples with empirical and theoretical data studying the hypotheses. Section 5 concludes with a discussion of the findings and implications for theory and practice. 


\section{Theoretical background}

\section{$2.1 \quad$ The model}

The used model of spatial coalition formation has been presented in De Ridder and Rusinowska (2008). There are $n$ players, here political parties trying to form a majority coalition $S$ and deciding on the so-called coalition position $x_{S}$ being a formal representation of the policy agreement of a coalition. Party $i \in N$, where $N$ denotes the set of all parties, has a weight $w_{i}>0$, which is based on the number of seats in parliament it possesses. In the model, each party $i$ may choose a policy position $x_{i}$ from an $m$-multidimensional Euclidean policy space $\mathbb{R}^{m}, m \geq 1$. A distance between two positions $x_{i}=\left(x_{i 1}, \ldots, x_{i m}\right)$ and $x_{j}=\left(x_{j 1}, \ldots, x_{j m}\right)$ is given by

$$
d\left(x_{i}, x_{j}\right)=\sqrt{\sum_{k=1}^{m}\left(x_{i k}-x_{j k}\right)^{2}} .
$$

Parties have a certain amount of flexibility on the policy positions, i.e., they have their preferences defined in $\mathbb{R}^{m}$. Each player $i \in N$ is assumed to have an ideal position $x_{i}^{*} \in \mathbb{R}^{m}$. Preferences of a party on positions are expressed by the following rule: the closer position $x_{i}$ is to ideal $x_{i}^{*}$, the more preferred this position is to party $i$. Each player $i \in N$ has also a maneuvering space, an equivalent of the policy horizon by Warwick (2000), which consists of all positions acceptable to party $i$. The maneuvering space of party $i$ is modeled by a ball $M_{i}$ in $\mathbb{R}^{m}$, i.e., the set of policy positions with distances from the ideal position of the party not greater than the radius. Hence,

$$
M_{i}=\left\{y \in \mathbb{R}^{m} \mid d\left(x_{i}^{*}, y\right) \leq r_{i}\right\} .
$$

The radius $r_{i}$ of the maneuvering space $M_{i}$ defines the flexibility of party $i$. In this paper, we do not investigate how to measure the radii. Several methods of estimating analogous policy horizons are analyzed e.g. in Warwick (2005a).

Given coalition $S \subseteq N$ and the ideal positions $x_{i}^{*}$ for $i \in S$, all parties of the potential coalition $S$ have to agree on a coalition position $x_{S}$. In the next subsection, we describe two alternative procedures for forming a coalition and choosing its position. Although the procedures differ from each other, a common assumption is that no party will agree on a position which does not belong to its maneuvering space. So, a necessary condition for a coalition $S$ to be formed is a non-empty intersection of the maneuvering spaces of its members. We call this a feasible coalition. The position $x_{S}$ of the formed coalition $S$ must belong to the intersection:

$$
\bigcap_{i \in S} M_{i} \neq \emptyset, \quad x_{S} \in \bigcap_{i \in S} M_{i}
$$

A similar assumption is adopted in the policy-horizon model: 'With horizons, there are definite limits to the willingness of parties to compromise on policy in order to participate in government; beyond those limits, parties would prefer to remain in opposition' (Warwick, 2000, p. 39). The concept of the maneuvering space of a party in our model is therefore equivalent to the policy horizon considered by Warwick. An illustration of the model for three-parties in two dimensional policy space is given in Figure 1. 


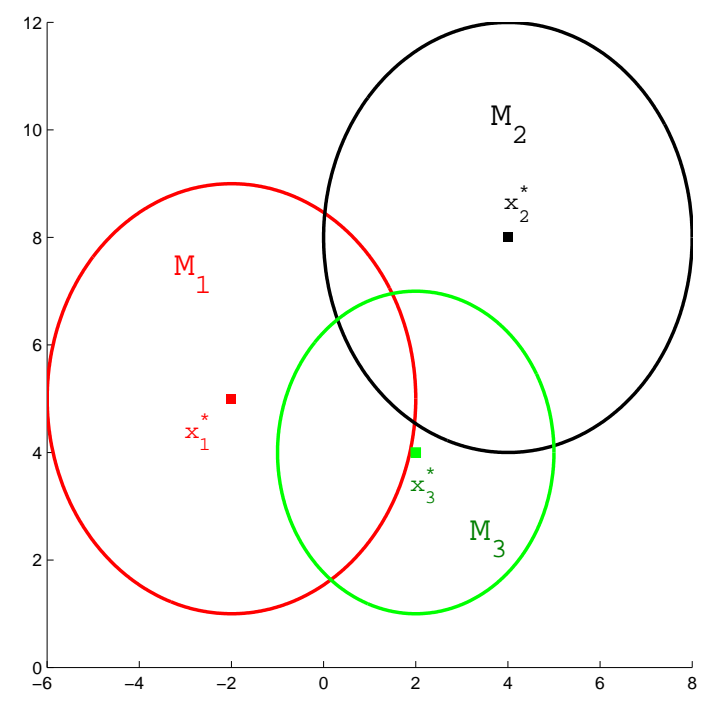

Figure 1: Illustration of the model with three parties in 2D policy space

\subsection{Procedures}

The focus of the model differs from the approach by Warwick in the procedures of forming a coalition. Given the parties' maneuvering spaces (determined by the ideal points and the radii), and the parties' weights, if the intersection of the maneuvering spaces of all members of a coalition is non empty, a procedure of forming that coalition determines uniquely the policy position of the coalition. Two procedures are considered: a step-by-step procedure and a simultaneous procedure. These two procedures coincide with the distinction in political science literature between hierarchal and non-hierarchal coalition formation (Laver \& Schofield, 1990).

The first kind of procedure, the hierarchal view, sees ' ... coalition building as a process in which actors with similar policy preferences first get together in some sort of provisional alliance and, only after this has been done ..., do they cast around for other coalition partners, adding these until the formation criterion is satisfied' (Laver \& Schofield, 1990, p. 140). The proto-coalition model of Grofman (1982) is such a hierarchial model. The step-by-step procedure presented here is a hierarchical procedure. Although it is difficult to look behind the often closed doors of coalition negotiations, e.g. Ireland, Belgium, and Denmark have known instances of this step-by-step approach (Müller \& Strøm, 2003).

In the step-by-step procedure of forming a certain coalition $S$, first parties 1 and 2 negotiate and will reach an agreement (coalition position $x_{\{1,2\}}$ ) if their maneuvering spaces overlap. This coalition position is determined by choosing a position in the intersection of their maneuvering spaces and taking the weights of the players into account. To be more precise, when determining $x_{\{1,2\}}$, parties 1 and 2 each choose a position (called the negotiation position) $\widetilde{x}_{1}$ and $\widetilde{x}_{2}$ in the intersection of the maneuvering spaces such that the distance of that position to the ideal point of the party is minimal. The coalition position $x_{\{1,2\}}$ is then the gravity center (a weighted average) of the negotiation positions. 


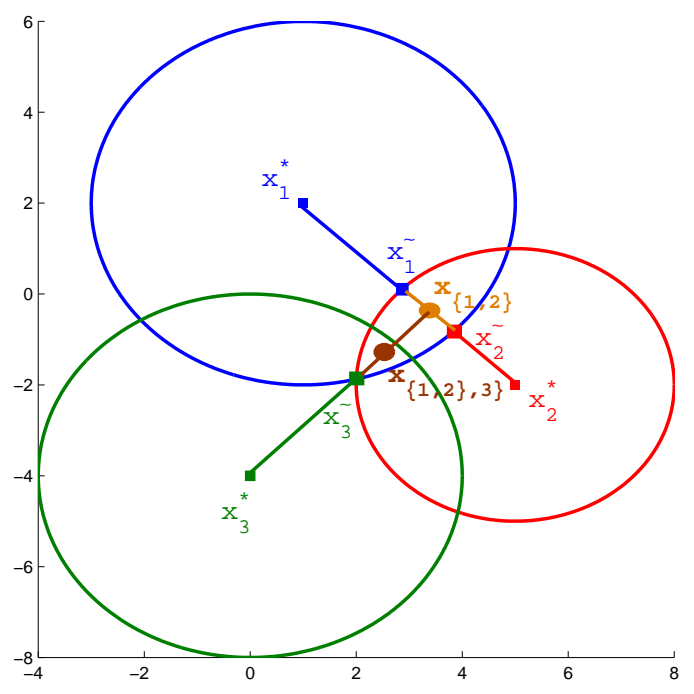

Figure 2: The step-by-step procedure, three parties in 2D policy space

When party 3 joins the negotiations, parties 1 and 2 operate as proto-coalition $\{1,2\}$ and an agreement with 3 is only reached if the maneuvering spaces of 1,2 , and 3 overlap. If so, coalition $\{1,2,3\}$ with position $x_{\{11,2\}, 3\}}$ is formed, which is the gravity center of the negotiation positions of the proto-coalition $\{1,2\}$ and party 3 . This procedure continues with adding new parties until coalition $S$ with position $x_{\bar{S}}$ has been reached, where $\bar{S}$ denotes an order in which the parties form coalition $S$. If parties' maneuvering spaces allow them to form a majority coalition, then the procedure finishes with forming such a coalition. If there is no majority coalition with a nonempty intersection of maneuvering spaces, then the step-by-step procedure leads to a minority coalition. An illustration of the step-by-step procedure of forming a three-party coalition is given in Figure 2.

With respect to a one-step procedure, Laver and Shepsle (1996) generalize political coalition formation as a process in which one party proposes a particular cabinet, which can be vetoed by all its members. In such a case, there are no proto-coalitions which form intermediate steps before a definitive coalition is reached. Non-hierarchical coalition formation is a process in which all the parties of a coalition sit round the table to negotiate simultaneously. In the overview of coalition formation in Western-Europe, Müller and Strøm (2003) report many instances of such a way of bargaining. In the model, the simultaneous procedure looks as follows. If maneuvering spaces of parties 1,2, and 3 overlap, then the parties form coalition $S=\{1,2,3\}$ and their coalition position is $x_{S}=x_{\{1,2,3\}}$. The corresponding coalition position in the intersection of the three maneuvering spaces depends on the weights of the players. Position $x_{S}$ is taken as the gravity center of the negotiation positions of all parties in question. An illustration of the simultaneous procedure of forming a three-party coalition is given in Figure 3.

Beware that respective outcomes of the step-by-step procedure and the simultaneous procedure are usually different. According to the step-by-step procedure, coalition $\{1,2,3\}$ can form 


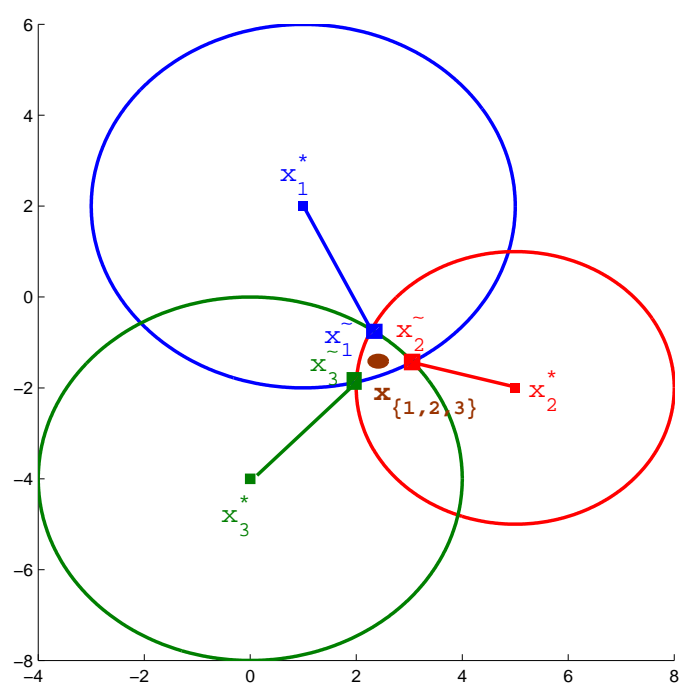

Figure 3: The simultaneous procedure, three parties in 2D policy space

in three different ways: first a bilateral agreement with two parties and then the third party 1,2 or 3 respectively joins. The simultaneous procedure predicts just one way of forming the coalition: all negotiate together. Hence, in spite of a cooperation between the same three parties, four different paths to form a coalition and four different coalition positions are discerned: $x_{\{\{1,2\}, 3\}}, x_{\{\{1,3\}, 2\}}, x_{\{\{2,3\}, 1\}}$, and $x_{\{1,2,3\}}$. Calculations have shown that the number of different paths and coalition positions can increase dramatically. In a coalition game with ten parties, $2^{10}-11=1013$ different $k$-party coalitions for $k \geq 2$, that is, simultaneously formed non-trivial coalitions, are possible. However, when taking different procedures into account, 4932045 different step-by-step $k$-party coalitions can be discerned plus 1013 simultaneously formed coalitions. In sum, if ten parties play a coalition game, there are 4933058 different ways of forming a non-trivial coalition. This number is calculated from the following formula:

$$
\frac{1}{2} \sum_{k=2}^{10}\left(\begin{array}{c}
10 \\
k
\end{array}\right) k ! .
$$

Disregarding some special conditions, the two procedures usually lead to different positions $x_{S}$ for the coalition and consequently different appreciations by the coalition members. Given the distance between the ideal position of a party and the coalition position, parties have a preference ranking over the different positions of the coalitions, over the different coalitions, and hence over the procedures to reach them. The closer a coalition agreement is to the ideal position of a party, the more this party will prefer the corresponding coalition and procedure. Hence, parties should also take the procedure to reach a coalition into consideration. The outcome of the step-by-step procedure is extremely path-dependent and depends on which party initiates the negotiations. For theoretical results comparing the different procedures of forming a three-party coalition, see De Ridder and Rusinowska (2008). 
In conclusion, the procedure of coalition formation should be a strategic resource in coalition formation and should play a role in coalition negotiations. However, empirical observations of how coalitions form show that procedures are usually not considered as a strategic resource, but procedure is rather the result of unwritten laws and traditions (e.g. Belgium, Finland, Luxembourg, and The Netherlands, Müller \& Strøm, 2003). An important observation is that in many multi-party democracies, it is a habit that the party that came out of the elections as the largest to get the initiative (from a head of state) for forming a coalition (Isaksson, 2005). Examples of countries in which this (more or less frequently) happens are The Netherlands, Sweden, Finland, Austria, Belgium, and Luxembourg (Müller \& Strøm, 2003). The idea behind this is that these initiative taking parties are supposed to lead the negotiations and to have an advantage in the bargaining situation. Ansolabehere et al. (2005) show that the party forming the coalition indeed receives a substantial bonus relative to its weight concerning the ministers posts it gets as compared to parties that only join the coalition. Also concerning policy rewards, the earlier a party is involved in coalition negotiations, the more this party is able to pull the negotiations towards its own ideas. In this way, this party can determine and influence the negotiations more and can get advantage out of it. This brings us to the first hypothesis:

\section{H1: Being a first-mover in coalition negotiations is advantageous.}

\section{$2.3 \quad$ Flexibility}

The flexibility during negotiations is in the model attributed to parties via maneuvering spaces. We will question another assumption often made in literature of coalition formation models, namely that political parties have a fixed position in policy space (Grofman, 1982; De Vries, 1999). Both during elections (Enelow \& Hinich, 1984; Budge, 1994; Van der Brug, 1999; Laver, 2005) and coalition negotiations (Warwick, 2000), the policy position of a party is more subject to change than is usually assumed. Both in the parliamentary and electoral arena, '...positions are not frozen or fixed; parties move in the policy space in different directions over time' (Timmermans, 2003, p. 9). Here, we focus on dynamics of policy positions in the coalition formation phase.

The idea is that in order to form a coalition, political parties will move their policy position, but only to a certain limit (Warwick, 2000) as formalized in the model by the maneuvering space. Coalition formation implies making a coalition agreement: a compromise between the members of a coalition on the ideological course of the coalition, consisting of a position for the coalition. As a consequence, parties participating in a coalition need to adjust their position in order to reach such an agreement (Martin \& Vanberg, 2004). The model assumes parties will only be willing to compromise if they can stay within their maneuvering space of acceptable positions.

The question now rises what is most in a party's interest: a big or small maneuvering space? When forming a two-party coalition, the answer is straightforward: being less flexible is never disadvantageous. If a coalition consists of only two parties, the more flexible party of the two will be forced to move its position more than the other. One can speak of a zero-sum situation: 
what one wins, is lost by the other. When forming a $k$-party coalition, for $k \geq 3$, the answer is less easy. Intuitively, one would consider that staying closer to a party's ideal position is also better in multi-party coalitions. So, a decrease in flexibility is always in a party's advantage. This question is not easy to analyze due to the amount of players involved. Therefore, we use the data and theoretical instances to study whether the following hypothesis holds:

H2: Being less flexible in coalition negotiations is more advantageous.

\subsection{Sharing power}

As a final point, we study the role of sharing power. Coalition formation has long been considered as a combination of achieving power, and simultaneously sharing this power with coalition partners. Coalition formation is therefore a delicate balance between on the one hand getting this power by compromising into the coalition, and on the other hand, forming a coalition which gives a party relatively the best power. In this tradition, the minimal winning (Von Neumann \& Morgenstern, 1944) and minimum size theory (Riker, 1962) have been formulated. Minimal winning coalitions are coalitions that contain enough members to be winning, but are not oversized. Minimal winning coalitions cannot miss any member without becoming losing. Minimum size coalitions contain enough weight to be winning, but not more than that. In line with this, one could reason that oversized coalitions imply sharing power with more partners and hence compromising with more partners than necessary. Less members in a coalition make it easier to reach an agreement which is closer to a party's ideal point. The corresponding hypothesis:

H3a: Being in a smaller (winning) coalition is more advantageous than being in an oversized coalition.

In a similar way, one can argue that forming a coalition with a stronger partner is not advantageous, since the stronger party may 'pull' the position of a formed coalition towards its own ideal position, formulated by hypothesis $3 \mathrm{~b}$ :

H3b: Increase of a party's weight is disadvantageous for its coalition partners.

\section{Illustration of the model}

The model discussed in the theoretical background section includes the three aspects of interest: procedures, flexibility of parties, and power sharing. Different procedures can lead to different positions and hence different results of coalition formation. The degree of flexibility of a party is important for the results of coalition formation. Power sharing has always been considered an important element of coalition formation. To study these issues, we perform calculations with the model using data from Dutch elections, next to several theoretical instances. The aim is to arrive at model implications, partly based on real-life counter-examples, which tell us whether the posed hypotheses always hold. In this section, we elaborate on the Dutch data used and provide insight in how the calculations have been performed.

The Netherlands seems to be a good choice to perform calculations based on the model. First, in The Netherlands, coalition governments are the standard, considering that the Dutch 
multi-party democracy only has had coalition governments since 1945 (Müller \& Strøm, 2003). Also, The Netherlands has a tradition of majority coalitions. Furthermore, two of the issues we highlight - procedures and flexibility - are important. Concerning procedures, the process of coalition formation is by far the longest in Western Europe with an average of 70.6 days. This could imply an important role for procedures. The first mover issue is relevant as it is characteristic for the Dutch coalition practice that the biggest party gets the initiative to form a coalition. Concerning flexibility, coalition agreements play an important role in coalition negotiations: each cabinet agrees on such a document as the course of action during their period of government. Data however show different ideal policy positions of Dutch parties (e.g. De Vries, 1999; Van der Brug, 1999) which implies compromises and hence flexibility of parties.

The calculations have been done with an algorithm that has been developed and reported in Sáiz et al. (2007). In short, in the step-by-step case, the algorithm determines the coalition position and preferences of parties for all coalitions at each possible path. In the simultaneous case, all possible coalitions are generated. For each coalition, the procedure computes the coalition position and preferences. The computation of the negotiation positions uses an external nonlinear programming algorithm. Data from 1998 and 2003 was available for our analysis. The 1998 and 2003 data are exemplars that deliver counter examples for the analysis of the hypotheses in a brief but effective way. The Dutch election result of 2003 is used to illustrate how the algorithms work. Table 1 shows this input. The names of the parties are the following:

CDA - Christian Democrats (Christen Democratisch Appel)

CU - Christian Union (Christen Unie)

D66 - Democrats 66 (Democraten '66)

GRL - Green Left (Groen Links)

LPF - List Pim Fortuyn (Lijst Pim Fortuyn)

PvdA - Labor Party (Partij van de Arbeid)

SP - Socialist Party (Socialistische Partij)

VVD - People's Party for Freedom and Democracy

(Volkspartij voor Vrijheid en Democratie)

Note that the SGP (Political Reformed Party) is not included in this table, as it was not included in the dataset from Klingemann et al. (2006) (in their Appendix IV it is explained that the election program for the collection of data was missing).

In the next section, we use this example together with the data of the Dutch election in 1998 to investigate the hypotheses. The model requires the ideal policy positions, a weight and a radius for each political party. The ideal policy positions are derived from a data set with policy positions of Dutch political parties on 56 dimensions from 1998 and 2003 (Klingemann et al., 2006). Because the model is working with spherical maneuvering spaces based on distance calculations, the data are all scaled between 0 and 10. The weight of the parties is determined by the amount of seats each party had in parliament (total of 150 seats). The radii that model the flexibility of the parties is relatively arbitrary for illustrative purposes and leave a degree of freedom for performing experiments. We have chosen two different ways to determine the radius: a radius similar for each party in the 1998 and 2003 case and a radius different for 
each party for the 1998 case. Where radii have the same size for all parties, they have been determined such that enough, but not too many, instances were found which could help us investigate the hypotheses.

Table 1: Example based on data for 2003

\begin{tabular}{l|cccccccc}
\hline & \multicolumn{8}{|c}{ Parties } \\
& CDA & CU & D66 & GRL & LPF & PvdA & SP & VVD \\
Radius & 30 & 30 & 30 & 30 & 30 & 30 & 30 & 30 \\
Weight & 44 & 3 & 6 & 8 & 8 & 42 & 9 & 28 \\
\hline
\end{tabular}

We only consider coalition positions of feasible winning coalitions, i.e., of majority coalitions of parties that have an overlap of their maneuvering spaces. Table 2 gives the majority coalitions containing CDA. As said earlier, in The Netherlands the biggest party gets the initiative for coalition formation. In 2003, this was the CDA. For each coalition reached with a certain procedure, the distance between the coalition position and the ideal position of the party are calculated. The $\{\mathrm{PvdA}, \mathrm{CDA}\}$ coalition leads to the same coalition position with both procedures as no third party joins here. However, for a coalition between CDA, PvdA, and LPF procedure plays a role as different procedures lead to different distances.

Table 2: Distances from ideal points for 2003 example, equal radius

\begin{tabular}{|c|c|c|c|c|c|c|c|c|c|}
\hline \multicolumn{10}{|c|}{ Step-by-Step Procedure } \\
\hline \multirow[t]{2}{*}{ Coalition } & \multirow[t]{2}{*}{ Seats } & \multicolumn{8}{|c|}{ Distance } \\
\hline & & $\mathrm{CU}$ & D66 & GRL & PvdA & SP & VVD & $\mathrm{LPF}$ & CDA \\
\hline$\{C D A, P v d A\}$ & 86 & - & - & - & 20.52 & - & - & - & 20.07 \\
\hline$\{\{C D A, P v d A\}, S P\}$ & 95 & - & - & - & 24.92 & 29.39 & - & - & 26.92 \\
\hline$\{\{\mathrm{CDA}, \mathrm{PvdA}\}, \mathrm{LPF}\}$ & 94 & - & - & - & 25.45 & - & - & 29.24 & 23.69 \\
\hline$\{\{C D A, S P\}, P v d A\}$ & 95 & - & - & - & 26.04 & 29.42 & - & - & 25.97 \\
\hline$\{\{\mathrm{CDA}, \mathrm{LPF}\}, \operatorname{PvdA}\}$ & 94 & - & - & - & 25.38 & - & - & 29.15 & 23.86 \\
\hline \multicolumn{10}{|c|}{ Simultaneous Procedure } \\
\hline & & $\mathrm{CU}$ & D66 & GRL & PvdA & $\mathrm{SP}$ & VVD & $\mathrm{LPF}$ & $\mathrm{CDA}$ \\
\hline$\{C D A, P v d A\}$ & 86 & - & - & - & 20.52 & - & - & - & 20.07 \\
\hline$\{C D A, P v d A, S P\}$ & 95 & - & - & - & 26.01 & 29.00 & - & - & 26.47 \\
\hline$\{\mathrm{CDA}, \mathrm{PvdA}, \mathrm{LPF}\}$ & 94 & - & - & - & 25.31 & - & - & 28.62 & 24.59 \\
\hline
\end{tabular}

Based on these distances, the preferences of the players can be calculated. The closer the coalition position to the ideal position of a party, the more the party will prefer the corresponding coalition and procedure. Table 3 reports this. As an example, CDA's most favorite option is to cooperate with PvdA. If CDA would cooperate with PvdA and SP, then the best procedure for CDA would be to negotiate first with SP alone. Note that we only consider preferences of the parties participating in the coalition.

In reality, the coalition that formed was $\{\mathrm{CDA}, \mathrm{VVD}, \mathrm{D} 66\}$. According to the model and the chosen radius, the maneuvering spaces of the parties do not overlap; $\{\mathrm{CDA}, \mathrm{VVD}, \mathrm{D} 66\}$ is less acceptable from a distance point of view than the coalitions that appear in the table. 
Table 3: Preference order for 2003, equal radius

\begin{tabular}{|c|c|c|c|c|c|c|c|c|c|}
\hline \multicolumn{10}{|c|}{ Step-by-Step Procedure } \\
\hline \multirow[t]{2}{*}{ Coalition } & \multirow[t]{2}{*}{ Seats } & \multicolumn{8}{|c|}{ Preference order } \\
\hline & & $\mathrm{CU}$ & D66 & GRL & PvdA & SP & VVD & LPF & $\mathrm{CDA}$ \\
\hline$\{C D A, P v d A\}$ & 86 & - & - & - & 1 & - & - & - & 1 \\
\hline$\{\{C D A, P v d A\}, S P\}$ & 95 & - & - & - & 2 & 2 & - & - & 7 \\
\hline$\{\{C D A, P v d A\}, L P F\}$ & 94 & - & - & - & 5 & - & - & 3 & 2 \\
\hline$\{\{C D A, S P\}, P v d A\}$ & 95 & - & - & - & 7 & 3 & - & - & 5 \\
\hline$\{\{C D A, L P F\}, P v d A\}$ & 94 & - & - & - & 4 & - & - & 2 & 3 \\
\hline \multicolumn{10}{|c|}{ Simultaneous Procedure } \\
\hline & & $\mathrm{CU}$ & D66 & GRL & PvdA & SP & VVD & LPF & $\mathrm{CDA}$ \\
\hline$\{C D A, P v d A\}$ & 86 & - & - & - & 1 & - & - & - & 1 \\
\hline$\{C D A, P v d A, S P\}$ & 95 & - & - & - & 6 & 1 & - & - & 6 \\
\hline$\{C D A, P v d A, L P F\}$ & 94 & - & - & - & 3 & - & - & 1 & 4 \\
\hline
\end{tabular}

\section{Hypotheses confronted with model instances}

To study the three hypotheses presented in Section 2, we generate cases based on empirical data used in Section 3 and theoretical instances. We aim to present these cases and examples as (counter-)instances which show whether the stated hypotheses hold. One should keep in mind that three issues are important in determining a coalition agreement: weights of the players, distances between members' policy positions, and the amounts of flexibility parties have. In other words, to determine whether a result is really due to the phenomenon in the hypothesis, we should pay attention to these three issues.

\subsection{Implications for procedure}

The first hypothesis says that being a first-mover in coalition negotiations is advantageous. In the 2003 case it can be observed that for LPF being the first mover was advantageous, since it prefers $\{\{\mathrm{CDA}, \mathrm{LPF}\}, \mathrm{PvdA}\}$ to $\{\{\mathrm{CDA}, \mathrm{PvdA}\}, \mathrm{LPF}\}$. In the same coalition we find a counter example due to PvdA which prefers to step in later.

Table 4: Weights and radius 45 for 1998 data

\begin{tabular}{l|cccccc}
\hline & \multicolumn{6}{|c}{ Parties } \\
& GRL & SP & PvdA & D66 & VVD & CDA \\
Radius & 45 & 45 & 45 & 45 & 45 & 45 \\
Seats & 11 & 5 & 45 & 14 & 38 & 29 \\
\hline
\end{tabular}

The data of 1998 show stronger counter-examples, described by Tables 4 and 5 . In the 1998 case, PvdA was the biggest party and had to take the initiative in coalition negotiations. Consider the three party coalition $\{\mathrm{PvdA}, \mathrm{SP}, \mathrm{CDA}\}$, two step-by-step and one simultaneous procedures where PvdA always had to be a first mover. In the two step-by-step procedures, CDA would be better off being a late instead of a first mover, although it prefers a simultaneous formation of that 3-party coalition to the step-by-step procedures. This also holds for SP, which in case of step-by-step formation rather joins as last member in the negotiations. Similar 
Table 5: Preference order for 1998 data, radius is 45

\begin{tabular}{|c|c|c|c|c|c|c|c|}
\hline \multicolumn{8}{|c|}{ Step-by-Step Procedure } \\
\hline \multirow[t]{2}{*}{ Coalition } & \multirow[t]{2}{*}{ Seats } & \multicolumn{6}{|c|}{ Preference order } \\
\hline & & GRL & $\mathrm{SP}$ & PvdA & D66 & VVD & $\mathrm{CDA}$ \\
\hline$\{\{P v d A, S P\}, C D A\}$ & 79 & - & 8 & 3 & - & - & 2 \\
\hline$\{\{P v d A, D 66\}, C D A\}$ & 88 & - & - & 5 & 7 & - & 4 \\
\hline$\{\{P v d A, C D A\}, S P\}$ & 79 & - & 4 & 1 & - & - & 7 \\
\hline$\{\{P v d A, C D A\}, D 66\}$ & 88 & - & - & 2 & 4 & - & 8 \\
\hline$\{\{\{P v d A, S P\}, D 66\}, C D A\}$ & 93 & - & 5 & 10 & 9 & - & 6 \\
\hline$\{\{\{P v d A, S P\}, C D A\}, D 66\}$ & 93 & - & 1 & 7 & 8 & - & 9 \\
\hline$\{\{\{P v d A, D 66\}, S P\}, C D A\}$ & 93 & - & 9 & 11 & 5 & - & 6 \\
\hline$\{\{\{P v d A, D 66\}, C D A\}, S P\}$ & 93 & - & 7 & 8 & 1 & - & 10 \\
\hline$\{\{\{P v d A, C D A\}, S P\}, D 66\}$ & 93 & - & 2 & 6 & 8 & - & 9 \\
\hline$\{\{\{P v d A, C D A\}, D 66\}, S P\}$ & 93 & - & 7 & 5 & 2 & - & 10 \\
\hline \multicolumn{8}{|c|}{ Simultaneous Procedure } \\
\hline & & GRL & SP & PvdA & D66 & VVD & CDA \\
\hline$\{P v d A, S P, C D A\}$ & 79 & - & 3 & 4 & - & - & 1 \\
\hline$\{P v d A, C D A, D 66\}$ & 88 & - & - & 9 & 3 & - & 3 \\
\hline$\{P v d A, D 66, S P, C D A\}$ & 93 & - & 6 & 12 & 6 & - & 5 \\
\hline
\end{tabular}

counter-examples are given by preferences of CDA and D66 when forming $\{\mathrm{PvdA}, \mathrm{CDA}, \mathrm{D} 66\}$ : both parties prefer to step in later. We can conclude that hypothesis 1 does not hold:

R1: Being a first mover is not always advantageous.

\subsection{Implications for flexibility}

The second hypothesis states that being less flexible in coalition negotiations is more advantageous. Although by being too rigid, a party may lose its option to be a part of the coalition, the intuition, fed by the case of two-party coalitions, says that less flexibility leads to a more advantageous coalition agreement for a party. The policy positions of Dutch parties are located in such a way, that even by playing with different radii, we did not find any example in the data that would contradict the hypothesis in question. This is why we constructed a one-dimensional theoretical example where the model shows that being less flexible can be a disadvantage.

Example 4.1 Consider a three-party example, in which parties 1 and 2 have the same weight, while the weight of party 3 is twice as big as the weight of party 1 and 2. All parties are equally flexible. We have

$$
N=\{1,2,3\}, \quad w_{1}=w_{2}, \quad w_{3}=2 w_{2}, \quad r_{1}=r_{2}=r_{3}=6, \quad x_{1}^{*}=0, \quad x_{2}^{*}=4, \quad x_{3}^{*}=-2 .
$$

The situation is illustrated in Figure 4. Since this is a one-dimensional example, the ideal positions are points (denoted in Figure 4 by squares) on a line, while the maneuvering spaces are intervals (denoted by two-headed arrows). The maneuvering spaces are

$$
M_{1}=[-6,6], \quad M_{2}=[-2,10], \quad M_{3}=[-8,4]
$$

and their intersections (two-headed arrows in Figure 4)

$$
M_{1} \cap M_{3}=[-6,4], \quad M_{1} \cap M_{2}=[-2,6], \quad M_{2} \cap M_{3}=M_{1} \cap M_{2} \cap M_{3}=[-2,4] \neq \emptyset .
$$




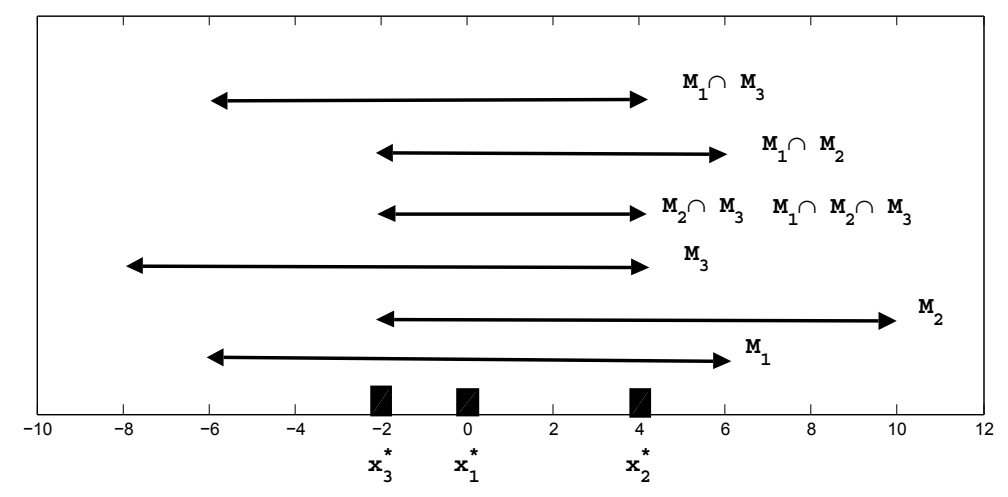

Figure 4: Counter-example "being less flexible can be a disadvantage". Ideal points (squares) and maneuvering spaces (two-headed arrows)

Hence, the necessary condition for coalition $\{1,2,3\}$ to be formed is satisfied. Let us consider the step-by-step procedure of forming $\{1,2,3\}$, in which first parties 1 and 2 form a coalition $\{1,2\}$, and then party 3 joins. The negotiation positions $x_{1}^{\{1,2\}}$ and $x_{2}^{\{1,2\}}$ of parties 1 and 2 are equal to their ideal positions, because the ideal points lie in the intersection of the maneuvering spaces. The coalition position is the gravity center of the negotiation positions with the same weights of parties 1 and 2 . Hence,

$$
x_{1}^{\{1,2\}}=0=x_{1}^{*}, \quad x_{2}^{\{1,2\}}=4=x_{2}^{*}, \quad x_{\{1,2\}}=2 \in M_{3}
$$

Next, party 3 joins proto-coalition $\{1,2\}$. Because $x_{3}^{*}$ and $x_{\{1,2\}}$ lie in the intersection of the maneuvering spaces, the negotiation positions of party 3 and proto-coalition $\{1,2\}$ are equal to $x_{3}^{*}=-2$ and $x_{\{1,2\}}=2$, respectively. Since the weight of party 3 is equal to the weight of $\{1,2\}$, we get

$$
x_{\{\{1,2\}, 3\}}=0=x_{1}^{*} .
$$

Hence, the step-by-step procedure of forming $\{\{1,2\}, 3\}$, in which first parties 1 and 2 form a coalition, and then party 3 joins, leads to the coalition position $x_{\{\{1,2\}, 3\}}$ which is the best possible position for party 1 .

Next, let us assume that party 1 becomes less flexible, that is, its new radius decreases to $r_{1}^{\prime}=3$. All remaining components of the example are unchanged. Then,

$$
M_{1}^{\prime}=[-3,3], \quad M_{1}^{\prime} \cap M_{2}=M_{1}^{\prime} \cap M_{2} \cap M_{3}=[-2,3] .
$$

Consider the same step-by-step procedure of forming $\{1,2,3\}$ with the new radius $r_{1}^{\prime}=3$. The new negotiation position $y_{1}^{\{1,2\}}$ of party 1 is the same as before (equals $x_{1}^{\{1,2\}}$ ), since its ideal point lies in the intersection of the maneuvering spaces. The new negotiation position $y_{2}^{\{1,2\}}$ of party 2 , and the new position $y_{\{1,2\}}$, which is the gravity center of $y_{1}^{\{1,2\}}$ and $y_{2}^{\{1,2\}}$ with equal weights $w_{1}=w_{2}$, are now

$$
y_{1}^{\{1,2\}}=x_{1}^{*}=0, \quad y_{2}^{\{1,2\}}=3, \quad y_{\{1,2\}}=\frac{3}{2} \in M_{3} .
$$


The new coalition position $y_{\{\{1,2\}, 3\}}$, as the gravity center of the negotiation positions $y_{\{1,2\}}$ and $x_{3}^{*}=-2$, with equal weights for $\{1,2\}$ and party 3 , is

$$
y_{\{\{1,2\}, 3\}}=-\frac{1}{4} .
$$

Hence, the step-by-step procedure of forming $\{\{1,2\}, 3\}$ results now in the coalition position $y_{\{\{1,2\}, 3\}}$ which is worse for party 1 than $x_{\{\{1,2\}, 3\}}$, for the case where party 1 is more flexible. This means that becoming less flexible made party 1 worse off.

To conclude, although the data have shown that less flexibility always seems to be advantageous to a party (apart from losing the option to be in the coalition), a theoretical counter example has illustrated how a decrease in flexibility can be a disadvantage for a party. Hence:

R2: When forming a k-party coalition, for $k \geq 3$, being less flexible is usually advantageous, but can theoretically be a disadvantage.

\subsection{Implications for power sharing}

Hypothesis 3a states that being in a minimal winning coalition is more advantageous than being in an oversized coalition. We have found several counter-examples in Dutch data where the hypothesis does not hold. Consider Dutch data after the 1998 elections (see Table 4). Here, we choose radii that are different as shown in Table 6 .

Table 6: Weights and different radii for 1998

\begin{tabular}{l|cccccc}
\hline & \multicolumn{7}{|c}{ Parties } \\
& GRL & SP & PvdA & D66 & VVD & CDA \\
Radius & 45 & 55 & 25 & 65 & 85 & 45 \\
Seats & 11 & 5 & 45 & 14 & 38 & 29 \\
\hline
\end{tabular}

Table 7 shows the preference order for this case. Note that under the two step by step procedures as well as the simultaneous procedure, PvdA finds the non-minimal winning coalition formed by PvdA, VVD and D66 more attractive than the minimal winning coalition $\{\mathrm{PvdA}$, VVD $\}$. Other counter-examples are presented in Table 5 which also concerns the Dutch data after the 1998 elections, but now with the same radius for each party equal to 45. SP prefers a non-minimal winning coalition $\{\{\{\mathrm{PvdA}, \mathrm{SP}\}, \mathrm{CDA}\}, \mathrm{D} 66\}$ to the coalition of PvdA, SP, and CDA formed by the simultaneous and two different step-by-step procedures. Similarly, D66 prefers the non-minimal winning coalition $\{\{\{\mathrm{PvdA}, \mathrm{D} 66\}, \mathrm{CDA}\}, \mathrm{SP}\}$ to the coalition of PvdA, CDA, and D66 formed by the simultaneous and two different step-by-step procedures. We then conclude that

R3a: Forming a minimal winning coalition is not always advantageous.

The last hypothesis (3b) says that an increase of a party's weight is disadvantageous for its coalition partners. This is true when forming a two-party coalition. The intuition is that in such a 'zero-sum' situation, the larger party will always be pulling the coalition position to its 
Table 7: Preference order with different radii for 1998

\begin{tabular}{|c|c|c|c|c|c|c|c|}
\hline \multicolumn{8}{|c|}{ Step-by-Step Procedure } \\
\hline \multirow[t]{2}{*}{ Coalition } & \multirow{2}{*}{ Number of seats } & \multicolumn{6}{|c|}{ Preference order } \\
\hline & & GRL & $\mathrm{SP}$ & PvdA & D66 & VVD & CDA \\
\hline$\{P v d A, V V D\}$ & 83 & - & - & 3 & - & 1 & - \\
\hline$\{\{P v d A, S P\}, V V D\}$ & 88 & - & 4 & 12 & - & 5 & - \\
\hline$\{\{P v d A, D 66\}, V V D\}$ & 97 & - & 10 & 1 & 11 & 6 & - \\
\hline$\{\{P v d A, V V D\}, S P\}$ & 88 & - & 8 & 7 & - & 4 & - \\
\hline$\{\{P v d A, V V D\}, D 66\}$ & 97 & - & 11 & 2 & 10 & 2 & - \\
\hline$\{\{\{P v d A, S P\}, D 66\}, V V D\}$ & 102 & - & 1 & 8 & 1 & 12 & - \\
\hline$\{\{\{P v d A, S P\}, V V D\}, D 66\}$ & 102 & - & 2 & 11 & 2 & 10 & - \\
\hline$\{\{\{P v d A, D 66\}, S P\}, V V D\}$ & 102 & - & 6 & 5 & 5 & 12 & - \\
\hline$\{\{\{P v d A, D 66\}, V V D\}, S P\}$ & 102 & - & 9 & 4 & 7 & 11 & - \\
\hline$\{\{\{P v d A, V V D\}, S P\}, D 66\}$ & 102 & - & 5 & 7 & 4 & 9 & - \\
\hline$\{\{\{P v d A, V V D\}, D 66\}, S P\}$ & 102 & - & 9 & 6 & 6 & 7 & - \\
\hline \multicolumn{8}{|c|}{ Simultaneous Procedure } \\
\hline & & GRL & $\mathrm{SP}$ & PvdA & D66 & VVD & CDA \\
\hline$\{P v d A, V V D\}$ & 83 & - & - & 3 & - & 1 & - \\
\hline$\{P v d A, S P, V V D\}$ & 88 & - & 7 & 10 & - & 3 & - \\
\hline$\{P v d A, D 66, V V D\}$ & 97 & - & 11 & 2 & 8 & 2 & - \\
\hline$\{P v d A, S P, D 66, V V D\}$ & 102 & - & 3 & 9 & 3 & 8 & - \\
\hline
\end{tabular}

own position, further away from its partner. It does not necessarily hold when forming a larger coalition. We illustrate this with the following theoretical example.

Example 4.2 Consider the situation of Example 4.1:

$$
\begin{aligned}
& N=\{1,2,3\}, \quad x_{1}^{*}=0, x_{2}^{*}=4, \quad x_{3}^{*}=-2, \quad r_{1}^{\prime}=3, r_{2}=r_{3}=6, \quad w_{1}=w_{2}, w_{3}=2 w_{2} \\
& M_{1}^{\prime}=[-3,3], \quad M_{2}=[-2,10], \quad M_{3}=[-8,4], \quad M_{1}^{\prime} \cap M_{2}=M_{1}^{\prime} \cap M_{2} \cap M_{3}=[-2,3] .
\end{aligned}
$$

As shown in Example 4.1, coalition position $y_{\{\{1,2\}, 3\}}=-\frac{1}{4}$ results from the step-by-step procedure of forming $\{\{1,2\}, 3\}$. Let the weight of party 1 increase towards $w_{1}^{\prime}=2 w_{2}=w_{3}$. The remaining components of the model remain unchanged. Considering the step-by-step procedure of forming $\{\{1,2\}, 3\}$ now leads to negotiation positions $z_{1}^{\{1,2\}}, z_{2}^{\{1,2\}}$ and coalition positions $z_{\{1,2\}}, z_{\{\{1,2\}, 3\}}$ being

$$
z_{1}^{\{1,2\}}=x_{1}^{*}=0, \quad z_{2}^{\{1,2\}}=3, \quad z_{\{1,2\}}=1 \in M_{3}, \quad z_{\{\{1,2\}, 3\}}=-\frac{1}{5} .
$$

Comparing the distance between coalition position $y_{\{\{1,2\}, 3\}}$ and the ideal point $x_{2}^{*}$ of party 2 and the distance between the new coalition position $z_{\{\{1,2\}, 3\}}$ and $x_{2}^{*}$, one can conclude that an increase of the weight of party 1 makes party 2 better off. This gives

R3b: When forming a $k$-party coalition, for $k \geq 3$, an increase of a party's weight may be an advantage for one of its coalition partners.

The artificial Example 4.2 shows the pure effect of an increase of a party's weight in a controlled setting keeping all remaining elements unchanged. This is of course not what happens in a parliament, since elections (usually) preceding coalition formation fix the weights of the parties. However, it can be used by parties defining a coalition formation strategy before 
elections. For example, in its campaign a party may be less negative with respect to another party whose bigger size might be beneficial. A similar tendency was found when considering the coalition PvdA, VVD and D66 and their distribution of seats after the 1994 and 1998 elections. D66 has less seats after the second election where both PvdA and VVD increased. However, the final distance of its ideal to the coalition position is smaller. To control the setting, we have constructed an instance using the data increasing the weight of only one party. Consider the case of Table 6 that presents the 1998 data with varying flexibility for the parties taking the real number of seats. The distance of the ideal of D66 to the compromise of coalition $\{\{\{\mathrm{PvdA}$, $\mathrm{SP}\}, \mathrm{D} 66\}, \mathrm{VVD}\}$ is 52.25. Let us now hypothetically assume that SP increases its weight by 30 , while the other parties keep their original weights. The distance of the ideal of D66 to the coalition position becomes 51.53, i.e., its position improves due to an increase of another party.

\section{Conclusions}

In spite of the many unwritten laws and traditions during coalition formation in countries as Italy, Luxembourg, The Netherlands, Belgium, and Ireland, political parties should be aware of the important role of the process of coalition formation. In this paper, we have shown how several aspects of this coalition process play an important role for the result of the coalition negotiations. We describe a formal model of coalition formation which considers political parties as players with ideal policy positions and maneuvering spaces that denote their flexibility. The output of the model is a set of feasible coalitions, which have a majority and whose members' maneuvering spaces overlap. The model describes which coalition position will be reached by the members given the procedure adopted.

We have focused on three aspects of coalition formation: procedure, flexibility, and power sharing. The following questions which political parties may take into account when forming a coalition were under study: Does procedure, being the order of coalition negotiation, matter? Is it more advantageous to be a first-mover in the coalition process? Is it better to be more or less flexible in coalition formation? Should we invite more parties to join to a (minimal) winning coalition or is it better to stay with the existing one(s)? Is it better to form a coalition with a stronger party or rather with a smaller one? Via analysis with empirical Dutch data and theoretical instances, we have arrived at several counter-examples that show the importance of procedure and give implications for political parties in coalition formation. The results have also implications for future coalition research. We discuss now both kinds of implications.

First, procedure matters. When forming a coalition, political parties should be aware of the important role procedure plays in determining the result of the coalition. However, earlier research has analyzed that there is not one procedure which is always best. The general practice of coalition formation is that procedures are generally formalized in pre-determined laws or traditions. The analysis shows that parties can benefit from manipulating the procedure.

Related to procedure is the second conclusion that being a first mover is not necessarily advantageous. This result is surprising in the sense that in many countries (e.g. The Netherlands, Belgium, Luxembourg, and Austria) the tradition is that the largest party can start the negoti- 
ations and determines who will negotiate first. Being involved early in the process is considered an advantage. However, from the model it appeared that this is not always the case. The rationale here is that, by studying coalition compromises the other coalition partners will reach without a party (assuming complete information), this party can estimate if this compromise is close to its ideal position. If it is, it is better to join later. If the compromise is not close, it may be better for the party to join earlier.

The third conclusion is that being less flexible is not necessarily advantageous. The practice, validated by the data, shows that being less flexible results in a (pre-)coalition compromise which is closer to a party's position. So, being less flexible pays off apart from the cases where a party cannot enter the coalition due to its rigid attitude. We presented a theoretical counter-example in which being less flexible is a disadvantage. Although being less flexible gives a better precoalition outcome, the final coalition position is worse for the party than the coalition position with the party being more flexible.

The final conclusions contradict the ideas of power sharing theories (as minimal winning theory). It appeared that forming a minimal winning coalition is not necessarily advantageous. Moreover, forming a coalition with a stronger party is not necessarily disadvantageous. So, it might pay off to share power with more and stronger parties than predicted by power sharing theory. To explain this counter-intuitive finding, for the minimal winning case it holds that new parties may determine a final coalition outcome closer to a party's ideal position, although this depends on the ideal positions of the new parties. For the stronger partner case, a strong party may determine a final coalition position which is closer to a party's position.

In sum, these four conclusions lead to the main message of the article. The analysis shows that the principles underlying coalition practice and the intuition around coalition theory do not necessarily hold. Coalition dynamics (procedure), being a first-mover, and policy flexibility, play a more important role than has so far been generally acknowledged in the coalition literature (with exceptions such as Brams et al., 2005, Warwick, 2005a, 2005b). We aim to reach the agenda of coalition research with this message. We leave other aspects of the research for future research; how to empirically determine a party's flexibility, development of more dynamic coalition models, empirical study of more countries, and analysis of the sensitivity for initial conditions in the step-by-step procedure.

\section{References}

Ansolabehere S, Snyder J, Strauss A, Ting M (2005) Voting weights and formateur advantages in the formation of coalition governments. American Journal of Political Science 49(3):550-563

Arnold T, Schwalbe U (2002) Dynamic coalition formation and the core. Journal of Economic Behavior and Organization 40:363-380

Austen-Smith D, Banks J (1988) Elections, coalitions and legislative outcomes. The American Political Science Review 82:405-422

Axelrod R (1970) Conflict of interest, A theory of divergent goals with applications to politics. 
Chicago: Marham

Baron D (1993) Government formation and endogenous parties. The American Political Science Review 87(1):34-47

Bloch F (1996) Sequential formation of coalitions in games with externalities and fixed payoff division. Games and Economic Behavior 14(1):90-123

Brams S, Jones M, Kilgour M (2005) Forming stable coalitions: The process matters. Public Choice 125(1-2):67-94

Budge I (1994) A new spatial theory of party competition: Uncertainty, ideology and policy equilibria viewed comparatively and temporally. British Journal of Political Science 24(4):443467

De Ridder A, Rusinowska A (2008) On some procedures of forming a multi-partner alliance, Journal of Economics and Management Strategy 17(2):443-487

De Vries M (1999) Governing with your closest neighbour: An assessment of spatial coalition formation theories. Enschede: Print Partners Ipskamp

Downs A (1957) An economic theory of democracy. New York: Harper and Row Publishers

Enelow J, Hinich M (1984) The spatial theory of voting. An introduction. Cambridge: Cambridge University Press

Grofman B (1982) A dynamic model of protocoalition formation in ideological n-space. Behavioral Science 27(1):77-90

Isaksson G (2005) From election to government: Principal rules and deviant cases. Government and Opposition 40(3):329-357

Klingemann H-D, Volkens A, Bara J, Budge I (Ed.) (2006) Mapping Policy Preferences II: Estimates for Parties, Electors and Governments in Central and Eastern Europe, European Union and OECD 1990-2003 Includes CD-ROM (Hardcover). Oxford: Oxford University Press Laver M (2005) Policy and the dynamics of political competition. American Political Science Review 99(2):263-281

Laver M, Shepsle K (1996) Coalitions and cabinet government. American Political Science Review 84(3):873-890

Laver M, Schofield N (1990) Multiparty government: The politics of coalition in Europe. Oxford: Oxford University Press

Martin L, Stevenson R (2001) Government formation in parliamentary democracies. American Journal of Political Science 45(1):33-50

Martin L, Vanberg G (2004) Policing the bargain: coalition government and parliamentary scrutiny. American Journal of Political Science 48(1):13-27 
Müller W, Strøm K (2003) Coalition governments in Western Europe. Oxford University Press Riker WH (1962) The theory of political coalitions. Yale University Press

Sáiz ME, Hendrix EMT, De Ridder A, Rusinowska A (2007) On the computation of negotiation positions and preferences in a spatial coalition model. Mansholt Working Paper MWP-39, Wageningen University

Tohmé F, Sandholm T (1999) Coalition formation processes with relief revision among bounded rational self-interested agents. Journal of Logic and Computation 9:793-816

Timmermans A (2003) High politics in the low countries. An empirical study of coalition agreements in Belgium and The Netherlands. Aldershot: Ashgate

Van Deemen A (1989) Dominant players and minimum size coalitions. European Journal of Political Research 17:313-332

Van Deemen A (1997) Coalition formation and social choice. Kluwer Academic Publisher

Van der Brug W (1999) Voters' perceptions and party dynamics. Party Politics 5(2):147-169

Volden C, Carrubba C (2004) The formation of oversized coalitions in parliamentary democracies. American Journal of Political Science 48(3):521-537

Von Neumann J, Morgenstern O (1944) Theory of games and economic behavior. Princeton: Princeton University Press

Warwick P (1998) Policy distance and parliamentary government. Legislative Studies Quarterly 23(3):319-345

Warwick P (2000) Policy horizons in West European parliamentary systems. European Journal of Political Research 38:37-61

Warwick P (2005a) When far apart becomes too far apart: Evidence for a threshold effect in coalition formation. British Journal of Political Science 35:383-401

Warwick P (2005b) Do policy horizons structure the formation of parliamentary governments?: The evidence from an expert survey. American Journal of Political Science 49(2):373-387 